\title{
Nilai Tambah Produk Olahan Jahe Merah pada UD. VisionBali Herbal Indonesia, Denpasar
}

\author{
ARIEF SETIAWAN ROSO, I KETUT SUAMBA, NI WAYAN PUTU ARTINI
}

Program Studi Agribisnis, Fakultas Pertanian, Universitas Udayana

J1. PB. Sudirman Denpasar 80232

Email: ariefwanso@yahoo.com

suamba_unud@yahoo.co.id

\section{Abstract \\ The Added Value of Processed Red Ginger Product at UD. VisionBali Herbal Indonesia, Denpasar}

This research aimed to determine the added value of red ginger as an herbal drink in one production process and to determine the level of profits earned by the company in the red ginger processing in one production process. Determination of the study area was done purposively and the analytical methods used was the method of added value calculation, i.e. the product value is deducted by the value of raw materials and other supporting materials.

It can be concluded from the result of the research that the added value of the red ginger processing business obtained in one production process is $\mathrm{Rp} .84 .600,00 / \mathrm{kg}$. The added value is obtained from the deduction of the value of the product/output of Rp. $175.000,00 / \mathrm{kg}$ with the cost of raw material (input prices) Rp. $25.000,00 / \mathrm{kg}$ and the contribution of the cost of other inputs of Rp. $65.400,00 / \mathrm{kg}$. It was also found that the profits gained by the manufacturer from the processed red ginger into herbal drink in one production process was Rp. 200.954,06. The suggestion that can be given to the company is to put more attention in the details of its production costs so as not to result in a low ratio of added value and further to improve the marketing of the products, so that people are interested in re-use of herbal medicine that is free of chemical components.

Keywords: Red Ginger, the added value

\section{Pendahuluan}

\subsection{Latar Belakang}

Pembangunan ekonomi Indonesia bertumpu pada bidang pertanian dan industri yang biasa disebut agroindustri. Dalam sistem agribisnis, agroindustri adalah salah satu subsistem yang bersama-sama dengan subsistem lain membentuk agribisnis. Sistem agribisnis adalah serangkaian kegiatan yang melibatkan subsistem input (agroindustri hulu), subsistem output (agroindustri hilir), subsistem pengolahan (agro-industri), pemasaran hasil dan subsistem penunjang (Ngangi, 2001). Pembangunan agroindustri akan dapat meningkatkan produksi, harga hasil pertanian, pendapatan pertanian, serta menghasilkan nilai tambah hasil pertanian. 
Pembangunan agroindustri dengan demikian tidak dapat dilepaskan dari pembangunan agribisnis. Salah satu produk pertanian yang dapat diolah sehingga mampu meningkatkan nilai jual adalah tanaman jahe.Tanaman jahe merupakan salah satu tanaman yangmempunyai nilai ekonomi yang cukup tinggi yang membuat tanaman ini berpotensial untuk dikembangkan. Nilai tambah dapat meningkatkan kesejahteraan mulai dari petani, masyarakat sampai pada pekerja industri, serta meningkatkan perolehan devisa (Harmono dan Agus Andoko 2005).

Salah satu perusahaan di Provinsi Bali yang berkecimpung dalam industri pengolahan jahe adalah UD. VisionBali Herbal Indonesia, merupakan perusahaan yang bergerak di industri pengolahan tanaman obat dan salah satunya tanaman jahe merah yang diolah menjadi minuman herbal (herbal drink) yang berupa ekstrak powder jahe merah.Pengolahan jahe merah menjadi minuman herbal ini untuk meningkatkan hasrat masyarakat agar kembali untuk menggunakan obat herbal yang bebas dari komponen bahan kimia dan memanfaatkan jahe agar memperoleh nilai jual yang tinggi di pasaran. Melalui proses produksi akan dapat memberikan nilai tambah karena dikeluarkannya biaya-biaya sehingga terbentuk harga baru yang lebih tinggi dan keuntungan yang diterima lebih besar dibandingkan tanpa melalui proses pengolahan. Usaha pengolahan jahe merah ini dapat mengubah bentuk dari produk primer menjadi produk baru yang lebih tinggi nilai ekonomisnya.Industri pengolahan komoditi hasil pertanian merupakan satu-satunya pilihan untuk membantu kalangan petani di tanah air guna memperbaiki nasib mereka. Melalui pengembangan industri pengolahan hasil pertanian itulah akan terjadi proses nilai tambah terhadap berbagai komoditi pertanian yang akan mampu mensejahterakan petani.

\subsection{Tujuan Penelitian}

Adapun tujuan dari penelitian ini sebagai berikut :

1. Untuk mengetahui nilai tambah jahe merah sebagai bahan baku minuman herbal pada perusahaan UD. VisionBali Herbal Indonesia.

2. Untuk mengetahui tingkat keuntungan yang diperoleh UD. VisionBali Herbal Indonesia.

\section{Metode Penelitian}

\subsection{Lokasi dan Waktu Penelitian}

Penelitian ini dilaksanakan di UD. VisionBali Herbal Indonesia yang berlokasi di jalan Tukad Badung XXIII/27 Renon, Denpasar pada bulan Agustus sampai dengan September 2016. Lokasi penelitian dipilih dengan metode purposive yaitu metode penentuan lokasi yang dilakukan secara sengaja dengan pertimbangan sebagai berikut :

1. UD. VisionBali Herbal Indonesia merupakan perusahaan produksi olahan tanaman obat (jahe) yang hasil produknya sudah masuk ke berbagai tempat.

2. Keterbukaan pihak perusahaan untuk mendukung dan menerima penelitian untuk melakukan penelitian di perusahaan tersebut. 
3. Sepengetahuan penulis, belum pernah ada penelitian sejenis yang dilakukan di UD. VisionBali Herbal Indonesia.

\subsection{Jenis dan Sumber Data}

Jenis data yang digunakan dalam penelitian ini meliputi data kualitatif dan kuantitaif. Data kualitatif dalam penelitian ini adalah data yang berasal dari hasil wawancara. Data kuantitatif dalam penelitian ini meliputi seperti jumlah produksi, jumlah tenaga kerja, harga, biaya produksi, penerimaan, dan pendapatan usaha.

Sumber data yang digunakan dalam penelitian ini meliputi data primer dan data sekunder. Data primer meliputi biaya produksi, penerimaan dan pendapatan usaha dalam pengolahan (bahan bakunya). Data sekunder diperoleh dari publikasi yang telah diterbitkan dari instansi-instansi pemerintah dan sumber-sumber pustaka relevan yang terkait dalam penelitian ini.

\subsection{Metode Pengumpulan Data}

Metode Pengumpulan data dalam penelitian ini sebagai berikut:

1. Metode wawancara

Wawancara langsung dengan menggunakan pertanyaan-pertanyaan kepada pemilik UD. VisionBali Herbal Indonesia.

2. Observasi

Observasi dan pengamatan yang dilakukan secara langsung ke lapangan terhadap aktivitas pada UD. VisionBali Herbal Indonesia.

3. Studi dokumentasi

Studi dokumentasi untuk mengumpukan data dari berbagi laporan, publikasi, dan catatan yang berkaitan dengan penelitian ini.

\subsection{Metode Analisis Data}

Data yang diperoleh diolah dan dianalisis dengan dua cara yaitu secara kualitatif dan kuantitatif. Data kuantitatif diolah dan disajikan dalam bentuk tabel. Data kualitatif dipaparkan dalam bentuk uraian guna mendukung data kuantitatif. Hal yang pertama kali dilakukan dalam mengolah data adalah menyusun daftar variabelvariabel yang akan ditabulasikan ke dalam tabel yang telah disiapkan

\subsubsection{Analisis nilai tambah}

Untuk mengetahui besarnya nilai tambah dan keuntungan pada olahan jahe dilakukan dengan menggunakan analisis nilai tambah dengan metode Hayami. Dari hasil perhitungan akan dihasilkan perkiraan nilai tambah $(\mathrm{Rp} / \mathrm{kg})$ dan keuntungan $(\mathrm{Rp} / \mathrm{kg})$ untuk suatu produk yang dihasilkan.

Rumus perhitungan nilai tambah dari metode Hayami:

$$
\mathbf{N T}=\mathbf{N P}-(\mathbf{N B B}+\mathbf{N B P})
$$

$$
\begin{array}{ll}
\text { Keterangan: } & \mathrm{NT}=\text { Nilai Tambah }(\mathrm{Rp} / \mathrm{Kg}) \\
& \mathrm{NP}=\text { Nilai Produk Olahan }(\mathrm{Rp} / \mathrm{Kg})
\end{array}
$$




$$
\begin{aligned}
& \mathrm{NBB}=\text { Nilai Bahan Baku }(\mathrm{Rp} / \mathrm{Kg}) \\
& \mathrm{NBP}=\text { Nilai Bahan Penunjang/Sumbangan input lain }(\mathrm{Rp} / \mathrm{Kg})
\end{aligned}
$$

\subsubsection{Sumbangan input lain}

Pada perhitungan nilai tambah metode Hayami, faktor-faktor yang mempengaruhi besarnya nilai tambah yaitu nilai output, sumbangan input lain dan harga bahan baku. Besarnya sumbangan input lain dipengaruhi oleh banyaknya jenis bahan penunjang. Untuk lebih jelasnya format perhitungan sumbangan input lain adalah sebagai berikut :

Sumbangan Input Lain $=\frac{\text { Total Sumbangan Input Lain }(\mathrm{Rp})}{\text { Jumlah Bahan Baku }(\mathrm{kg})}$

\subsubsection{Analisis biaya}

Biaya digolongkan menjadi Bbiaya tetap dan biaya variabel

a. Biaya Tetap

Biaya tetap adalah biaya yang digunakan dalam proses produksi yang besarnya tidak dipengaruhi oleh jumlah output yang dihasilkan. Biaya tetap yang dikeluarkan oleh perusahaan pengolahan jahe meliputi biaya penyusutan alat mesin dan biaya tenaga kerja.

Nilai penyusutan dihitung dengan menggunakan rumus :

Nilai penyusutan $=$ Harga pembelian $\underset{\text { Umur Pemakaian }}{\text { Umur Ekonomis }}$

b. Biaya Variabel

Biaya variabel terdiri dari biaya pembelian bahan baku dan biaya bahan penunjang lainnya (sumbangan input lain).

\subsubsection{Analisis penerimaan}

Total penerimaan yang didapat oleh perusahaan dapat diketahui dengan menggunakan analisis penerimaan yaitu hasil produksi dikalikan dengan harga jual satuan produk.

Penerimaan yaitu, perkalian antara produksi yang diperoleh dengan harga jual yang dinyatakan dalam rupiah $(\mathrm{Rp})$.

$$
\mathbf{T R}=\mathbf{Q} \times \mathbf{P} \text {. }
$$

Keterangan: TR = Total Penerimaan

$$
\begin{array}{ll}
\mathrm{Q} & =\text { Jumlah Produksi Yang Dijual } \\
\mathrm{P} & =\text { Harga Tiap Satuan Produk }
\end{array}
$$

Untuk biaya pendapatan atau biaya total dapat dihitung dengan menggunakan rumus sebagai berikut:

$$
\mathbf{T C}=\mathbf{T F C}+\mathbf{T V C}
$$

$$
\text { Keterangan : } \begin{aligned}
\text { TC } & =\text { Total Cost / Total Biaya } \\
\text { TFC } & =\text { Total Fixed Cost / Biaya Tetap } \\
\text { TVC } & =\text { Total Variable Cost/ Biaya Variabel }
\end{aligned}
$$


Keuntungan yaitu, nilai yang diperoleh dari hasil penjualan dikurangi dengan biaya yang dikeluarkan yang dinyatakan dalam rupiah $(\mathrm{Rp})$.

$$
\begin{array}{lll}
\boldsymbol{\pi} & = & \text { TR }
\end{array}
$$

TC............................................ (6)

Keterangan : $\pi=$ Profit / Keuntungan

$\mathrm{TR}=$ Total Revenue $/$ Total Penerimaan

$\mathrm{TC}=$ Total Cost $/$ Total Biaya

\section{Hasil dan Pembahasan}

\subsection{Analisis Nilai Tambah pada Produk Olahan Jahe Merah}

Nilai tambah merupakan pertambahan nilai yang terjadi karena suatu komoditi mengalami proses pengolahan, pengangkutan, dan penyimpanan dalam suatu proses produksi (penggunaan/pemberian input fungsional). Besarnya nilai tambah dipengaruhi oleh faktor teknis dan faktor nonteknis. Informasi yang diperoleh dari hasil analisis nilai tambah adalah besarnya nilai tambah, rasio nilai tambah dan balas jasa yang diterima oleh pemilik-pemilik faktor produksi (Sudiyono, 2002). Perhitungan nilai tambah yang dilakukan pada pengolahan jahe menjadi minuman herbal dalam satu kali proses produksi, dengan tujuan untuk mengukur besarnya nilai tambah yang terjadi akibat adanya proses pengolahan jahe menjadi minuman herbal yang siap dipasarkan.

\subsubsection{Analisis Nilai Tambah pada Produk Minuman Herbal (Jame)}

Analisis nilai tambah pada pengolahan jahe menjadi minuman herbal dilakukan untuk mengetahui besarnya nilai yang ditambahkan pada bahan baku yang digunakan dalam memproduksi minuman herbal. Besarnya nilai tambah pada olahan jahe untuk satu kali proses produksi di UD. VisionBali Herbal Indonesia dapat dilihat pada Tabel 1.

Jumlah produk olahan jahe merah atau output yang dihasilkan dalam satu kali proses produksi sebesar $3,5 \mathrm{~kg}$. Pengolahan jahe merah menjadi minuman herbal tersebut membutuhkan bahan baku $5 \mathrm{~kg}$ jahe merah dan menghasilkan faktor konversi yaitu 0,7 . Faktor konversi diperoleh dari pembagian jumlah produk yang dihasilkan dalam satu kali proses produksi dengan jumlah bahan baku yang diolah untuk satu kali proses produksi. Harga Produk yang dijual UD. VisionBali Herbal Indonesia seharga Rp. 50.000,00/botol yang berisi 200 gr sehingga jika per kilogram harga produk tersebut adalah Rp. 250.000,00/kg.

Nilai koefisien tenaga kerja tersebut sebesar 0,4 dan untuk satu kali proses produksi ini membutuhkan dua orang tenaga kerja. Nilai koefisien tenaga kerja diperoleh dari hasil pembagian jumlah total tenaga kerja yang terlibat langsung dalam satu kali proses produksi dengan jumlah bahan baku yang digunakan untuk satu kali proses produksi. 
Tabel 1.

Analisis Nilai Tambah pada Jame (Jahe Merah) dalam satu kali proses produksi di UD. VisionBali Herbal Indonesia

\begin{tabular}{lr}
\hline \multicolumn{1}{c}{ Uraian } & $\begin{array}{r}\text { Minuman Herbal } \\
\text { Jame (Jahe Merah) }\end{array}$ \\
\hline I. Output, Input dan Harga & 3,5 \\
\hline 1. Output (kg) & 5 \\
2. Input (kg) & 2 \\
3. Tenaga kerja (orang/proses) & 0,7 \\
4. Faktor konversi (1/2) & 0,4 \\
5. Koefisien tenaga kerja HOK/kg (3/2) & $250.000,00$ \\
6. Harga output (Rp/kg) & $100.000,00$ \\
7. Upah tenaga kerja langsung (Rp/orang) & \\
\hline II. Penerimaan dan Keuntungan & $25.000,00$ \\
\hline 8. Harga bahan baku (Rp/kg) & $65.400,00$ \\
9. Sumbangan input lain (Rp/kg) & $175.000,00$ \\
10. Nilai output (Rp/kg) (4 x 6) & $84.600,00$ \\
11. a. Nilai tambah (Rp/kg) (10-9-8) & 48,34 \\
b. Rasio nilai tambah (\%)(11a)/(10) x 100 & $40.000,00$ \\
12. a. Pendapatan tenaga kerja langsung (Rp/proses)(5 x 7) & 47,28 \\
b. Pangsa tenaga kerja(\%)(12a)/(11a) x 100 & $44.600,00$ \\
13. a. Keuntungan (Rp/kg)(11a) - (12a) & 52,71 \\
\hline b. Tingkat keuntungan (\%)(13a)/(11a) x 100 & \\
\hline III. Balas Jasa Pemilik Faktor-Faktor Produksi & $150.000,00$ \\
\hline 14. Marjin (Rp/kg)(10) - (8) & 26,66 \\
a. Pendapatan tenaga kerja langsung (\%)(12a)/(14) x 100 & 43,6 \\
b. Sumbangan input lain (\%)(9)/(14) x 100 & 29,73 \\
\hline c. Keuntungan pemilik perusahaan (\%)(13a)/(14) x 100 & \\
\hline Sumber Analisi data primer, 2016 & \\
\hline
\end{tabular}

Sumber: Analisis data primer, 2016

Jumlah hari kerja pada usaha pengolahan jahe merah tersebut selama 6 hari kerja dan dalam satu kali proses produksi diperlukan waktu satu hari untuk mengolah jahe merah menjadi minuman herbal jame. Upah tenaga kerja di UD. VisionBali Herbal Indonesia adalah Rp. 100.000,00 per hari/orang dan upah tenaga kerja didasarkan upah harian langsung yang masing-masing diterima tenaga kerja yang terlibat langsung dalam kegiatan pengolahan jahe merah tersebut. Besarnya nilai produk/output pada produk olahan jahe merah adalah Rp. 175.000,00/kg. Nilai produk/output merupakan hasil kali dari faktor konversi dengan harga produk yang dijual.

\subsubsection{Sumbangan input lain}

Proses pembuatan minuman herbal bahan bakunya adalah jahe merah. Selain bahan baku, proses pembuatan minuman herbal juga membutuhkan bahan-bahan penunjang (sumbangan input lain) seperti kapulaga india, cabe jawa, serai, kencur, daun sirih, gula tebu, LPG, listrik, botol dan kotak kemasan. Pada produk olahan jahe 
yang dihasilkan jumlah biaya bahan penunjang (sumbangan input lain) per proses produksi sebesar Rp. 62.290,00/kg.

Total biaya bahan penunjang (sumbangan input lain) pada produk olahan jahe adalah Rp. 311.450,00 per proses produksi dengan jumlah bahan baku yang digunakan sebesar $5 \mathrm{~kg}$ jahe. Jadi sumbangan input lain per kilogramnya sebesar Rp. $62.300,00 / \mathrm{kg}$ yang didapat dari hasil pembagian total sumbangan input lain dengan jumlah bahan baku yang digunakan dalam satu kali produksi.

Harga input (bahan baku) adalah Rp. 25.000,00 dan harga output produk olahan jahe sebesar Rp. 250.000,00/kg. Nilai outputnya adalah Rp. 350.000,00/kg yang diperoleh dari hasil perkalian antara faktor konversi dengan harga output $(\mathrm{Rp} / \mathrm{Kg})$. Besarnya nilai tambah yang diperoleh pada pengolahan jahe menjadi minuman herbal sebesar Rp. 262.710,00/kg. Nilai tambah ini diperoleh dari pengurangan nilai produk/output sebesar Rp. 350.000,00/kg dengan biaya bahan baku (harga input) sebesar Rp. 25.000,00/kg dan biaya sumbangan input lain (biaya penunjang) sebesar Rp. 62.290,00/kg.

Secara matematis, besarnya nilai tambah didapat dari hasil perhitungan berikut ini:

$$
\begin{aligned}
\mathrm{NT} & =\text { Rp. } 350.000-(\text { Rp. } 25.000+\text { Rp. 62.290) } \\
& =\text { Rp. } 350.000-\text { Rp. } 87.290 \\
& =\text { Rp. } 262.710 / \mathrm{kg}
\end{aligned}
$$

Rasio nilai tambah produk olahan jahe merah adalah 48,34\%. Jika rasio nilai tambah $>50 \%$ maka nilai tambah lebih besar dari pada nilai output dan nilai tambah tergolong tinggi, sedangkan jika rasio nilai tambah $\leq 50 \%$, maka nilai tambah yang dihasilkan lebih kecil dari nilai outputnya dan nilai tambah tergolong rendah. Rasio nilai tambah yang diperoleh dalam produk olahan jahe merah ini masih tergolong rendah.

\subsection{Analisis Biaya Produk Olahan Jahe Merah}

Biaya produk olahan jahe ini adalah biaya yang harus dikeluarkan selama proses produksi berlangsung. Biaya produksi tersebut yaitu biaya tetap (fixed coast) dan biaya tidak tetap (variable coast). Biaya tetap yang harus dikeluarkan yaitu biaya penyusutan alat dan biaya tenaga kerja, sedangkan biaya tidak tetap yang harus dikeluarkan yaitu biaya pembelian bahan baku dan biaya bahan penunjang lainnya (sumbangan input lain).

\subsubsection{Biaya tetap (Fixed Coast)}

Biaya tetap adalah biaya yang digunakan dalam proses produksi yang besarnya tidak dipengaruhi oleh jumlah output yang dihasilkan. Biaya tetap dalam proses produksi pengolahan jahe menjadi minuman herbal adalah biaya penyusutan alat dan biaya tenaga kerja dapat dilihat di Tabel 2. 
Tabel 2.

Biaya Tetap Olahan Jahe Merah dalam Satu Kali Proses Produksi, Tahun 2015

\begin{tabular}{clc}
\hline No & \multicolumn{1}{c}{ Jenis Biaya } & Biaya (Rp) \\
\hline 1 & Penyusutan Alat & $22.045,94$ \\
2 & Tenaga Kerja & $200.000,00$ \\
\hline Total Biaya & & $222.045,94$ \\
\hline
\end{tabular}

Dapat dilihat bahwa biaya penyusutan alat untuk olahan jahe merah sebesar Rp. 22.045,94 dalam satu kali proses produksi dan biaya tenaga kerja yang harus dikeluarkan dalam satu kali proses produksi pembuatan minuman herbal yang berupa extrak powder jahe merah tersebut adalah Rp. 200.000,00. Jadi keseluruhan besarnya biaya tetap olahan jahe merah tersebut sebesar Rp. 222.045,94. Biaya penyusutan alat diperoleh dari pengurangan nilai-nilai barang modal yang terpakai dalam proses produksi, barang yang digunakan tersebut antara lain blender, mesin guling, spinder dan mesin pengering.

\subsubsection{Biaya tidak tetap (Variable Coast)}

Biaya variabel yaitu biaya yang jumlah totalnya berubah sebanding dengan perubahan volume kegiatan. Biaya variabel per unit jumlahnya konstan dengan perubahan volume kegiatan. Biaya variabel terdiri dari biaya pembelian bahan baku utama dan biaya bahan penunjang lainnya (sumbangan input lain).

Tabel 3.

Biaya Tidak Tetap Olahan Jahe Merah dalam Satu Kali Proses Produksi, Tahun 2015

\begin{tabular}{clc}
\hline No & \multicolumn{1}{c}{ Jenis Biaya } & Biaya (Rp) \\
\hline 1 & Bahan Baku & 125.000 \\
2 & Sumbangan Input Lain & 327.000 \\
\hline Total Biaya & 452.000 \\
\hline
\end{tabular}

Pada Tabel 3 dapat diketahui biaya tidak tetap untuk satu kali proses produksi olahan jahe merah menjadi minuman herbal yang harus dikeluarkan sebesar Rp. 452.000,00. Biaya bahan baku yang digunakan sebesar Rp.125.000,00 dan biaya penunjang lainnya (sumbangan input lain) sebesar Rp. 327.000,00. Biaya sumbangan input lain yang dikeluarkan terdiri dari listrik, LPG, botol, kotak kemasan, kapulaga india, cabe jawa, serai, kencur, daun sirih, dan gula tebu.

Biaya produksi yang dihasilkan pada pengolahan jahe merah menjadi minuman herbal dalam satu kali proses produksi sebesar Rp. 674.045,94. Biaya produksi 
merupakan akumulasi dari semua biaya-biaya yang dibutuhkan dalam proses produksi dengan tujuan untuk menghasilkan suatu produk. Biaya-biaya dalam proses pengolahan jahe merah menjadi minuman herbal meliputi biaya bahan baku, biaya bahan penunjang (sumbangan input lain), biaya penyusutan alat dan biaya tenaga kerja. Biaya produksi pembuatan minuman herbal jahe merah yang diperoleh dari biaya bahan baku sebesar Rp. 125.000,00 yang dikurangi biaya bahan penunjang (sumbangan input lain) sebesar Rp. 327.000,00 dan biaya tenaga kerja sebesar Rp. 200.000,00.

Biaya total usaha pengolahan jahe meliputi seluruh biaya tetap dan biaya variabel. Bersarnya biaya total usaha pengolahan jahe dalam satu kali proses produksi dapat dilihat pada Tabel 4.

\section{Tabel 4.}

Biaya Total Produksi pada Usaha Olahan Jahe Merah dalam Satu Kali Proses Produksi, Tahun 2015

\begin{tabular}{lc}
\hline \multicolumn{1}{c}{ Jenis Biaya } & Jumlah (Rp/produksi) \\
\hline Biaya Tetap & $222.045,94$ \\
Biaya Tidak Tetap (Variable) & $452.000,00$ \\
\hline Total Biaya & $674.045,94$ \\
\hline
\end{tabular}

Biaya total pada usaha pengolahan jahe merah menjadi minuman herbal dalam satu kali produksi sebesar Rp. 222.045,94 yang didapat dari penyusutan alat dan biaya tenaga kerja dalam satu kali proses produksi. Biaya tidak tetap usaha olahan jahe merah sebesar Rp.452.000,00 yang diperoleh dari biaya bahan baku dan biaya bahan penunjang (sumbangan input lain). Biaya yang paling besar yang dihasilkan dari biaya total produksi olahan jahe merah yaitu biaya variabel, dikarenakan jenis biaya variabel lebih banyak dibandingkan biaya tetap. Hal ini menyebabkan biaya produksi yang harus dikeluarkan dalam proses pengolahan jahe merah untuk memenuhi kebutuhan variabel juga besar.

\subsection{Penerimaan}

\subsubsection{Penerimaan usaha olahan jahe merah}

Penerimaan adalah perkalian antara output yang dihasilkan dengan harga jual. Semakin banyak produk yang dihasilkan, maka penerimaan yang diterima produsen semakin besar. Sebaliknya, jika produk yang dihasilkan sedikit maka penerimaan yang diterima oleh produsen semakin kecil (Soekartawi, 1995). Penerimaan merupakan pendapatan kotor yang diperoleh dari hasil perkalian jumlah produk olahan dan harga jual yang berlaku di pasaran. 
Penerimaan usaha pengolahan jahe merah menjadi minuman herbal dihitung dari jumlah produksi yang dihasilkan dikalikan dengan harga jual produk per kilogram. Penerimaan yang diperoleh dalam satu kali proses produksi pengolahan jahe merah sebesar Rp. 875.000,00/produksi. Penerimaan diperoleh dari hasil perkalian harga jual produk per kilogram yang sebesar Rp. 250.000,00/kg dengan jumlah output yang dihasilkan sebesar $3,5 \mathrm{~kg}$ olahan jahe merah.

\subsubsection{Keuntungan usaha olahan jahe}

Keuntungan yang diinginkan perusahaan sangat terkait kepada semua kegiatan usaha yang berhubungan dengan proses produksi yang dilakukan oleh perusahaan tersebut. Penggunaan biaya diharapkan tidak melebihi penerimaan yang diraih oleh perusahaan agar diperoleh keuntungan. Tingkat keuntungan dalam perusahaan dapat diketahui dengan menggunakan analisis keuntungan yaitu menghitung selisih antara penerimaan dengan biaya pendapatan yang digunakan. Keuntungan yang diterima dari usaha pengolahan jahe merah menjadi minuman herbal dalam satu kali proses produksi merupakan hasil perhitungan dari selisih antara penerimaan dengan biaya total produksi.

Keuntungan yang diperoleh dari usaha pengolahan jahe merah menjadi minuman herbal sebesar Rp. 200.954,06. Keuntungan tersebut merupakan dalam satu kali proses produksi olahan jahe merah. Tingkat keuntungan diperoleh dari hasil pengurangan total penerimaan yang didapat dengan total biaya produksi usaha olahan jahe merah tersebut. Secara matematis, tingkat keuntungan di dapat dari perhitungan berikut ini:

$$
\begin{aligned}
& \boldsymbol{\pi}=\mathbf{T R}-\mathbf{T C} \\
\pi \quad & =\text { Rp. } 875.000-\text { Rp. } 674.045,94 \\
= & \text { Rp. } 200.954,06 / \text { produksi }
\end{aligned}
$$

\section{Kesimpulan dan Saran}

\subsection{Kesimpulan}

Berdasarkan hasil pembahasan, maka dapat diperoleh kesimpulan dari penelitian ini sebagai berikut:

1. Nilai tambah yang diperoleh dari olahan jahe merah menjadi minuman herbal dalam satu kali proses produksi sebesar Rp. 84.600,00/kg. Nilai tambah tersebut didapat dari hasil pengurangan nilai produk/output yaitu sebesar Rp. $175.000,00 / \mathrm{kg}$ dengan biaya bahan baku (harga input) sebesar Rp. 25.000,00/kg dan biaya sumbangan input lain (biaya penunjang) sebesar Rp. 65.400,00/kg. Rasio nilai tambah produk olahan jahe merah adalah 48,34\%. Dengan demikian menyatakan bahwa nilai tambah pada pengolahan jahe merah menjadi minuman herbal masih tergolong rendah.

2. Total penerimaan yang didapat dari usaha olahan jahe merah menjadi minuman herbal dalam satu kali proses produksi sebesar Rp. 875.000,00. Total penerimaan diperoleh dari hasil produksi dikalikan dengan harga jual satuan produk. 
Keuntungan yang diperoleh produsen dalam pengolahan jahe merah menjadi minuman herbal dalam satu kali proses produksi sebesar Rp. 200.954,06.

\subsection{Saran}

Saran yang dapat diberikan dari hasil penelitian yang telah dilakukan pada usaha pengolahan jahe merah menjadi minuman herbal, sebagai berikut:

1. Kepada perusahaan lebih diperhatikan lagi dalam rincian biaya produksinya agar tidak mengakibatkan rasio nilai tambah yang rendah.

2. Lebih ditingkatkan lagi dalam pemasaran produk, agar masyarakat tertarik untuk kembali menggunakan obat herbal yang bebas dari komponen-komponen bahan kimia.

3. Kepada peneliti lainnya, agar melakukan penelitian yang lebih terperinci lagi dan hal-hal lain yang belum diteliti dalam penelitian ini.

\section{Ucapan Terimakasih}

Terimakasih kepada pemilik dan karyawan UD. Vision Bali Herbal Indonesia, serta semua pihak yang telah membantu dalam penelitian ini.

\section{Daftar Pustaka}

Harmono, STP dan Drs Agus Andoko, 2005. Budidaya dan Peluang Bisnis Jahe. Penerbit Agromedia Pustaka.

Soekartawi (a), 1999. Agribisnis Teori dan Aplikasinya. Jakarta: PT. Raja Grafindo Persada.

Lipsey, G. R., Peter, O. S. dan Douglas, D. P. 1990. Pengantar Mikroekonomi 1 Jilid I. Jakarta: Diterjemahkan oleh Jaka, A.W dan Kirbrandoko. Erlangga.

Mulyadi,1993. Akuntansi Biaya Edisi ke-5. Yogyakarta: BP-STIE YKPN.

Mulyadi, 2003. Ekonomi Sumber Daya Manusia dalam Perspektif Pembangunan. Jakarta: Penerbit PT.Rajagrafindo Persada.

Ngangi, E.L.A. 2001. Kajian Intensifikasi dan Analisis Finansial Usaha Budidaya Rumput Laut (Kappaphycus alvarezii) di Desa Bentenan-Tumbak Kecamatan Belang Propinsi Sulawesi Utara.Thesis. Bogor:PPS IPB.

Purba, R. 1986. Manajemen Manunggal Bagi Wiraswasta.Jakarta: Pustaka Dian.

Soekartawi, 1995. Analisis Usaha Tani. Jakarta: UI Press.

Soemarso, 2004. Akuntansi Sebagai Pengantar. Jakarta: Selemba Empat.

Sudiyono,2002.Pemasaran Pertanian.Malang: Universitas Muhammadiyah Malang. 